\title{
THE CLASSIFICATION OF PARALLEL STRUCTURE MECHANISMS
}

Щелкунов Евгений Борисович - кандидат технических наук, доцент кафедры «Технология машиностроения» Комсомольского-на-Амуре государственного технического университета (Россия, Комсомольск-наАмуре). E-mail: ktm@knastu.ru.

Mr. Yevgeny B. Shchelkunov - PhD in Engineering, Associate Professor, Mechanical Engineering Department, Komsomolsk-on-Amur State Technical University (Russia, Komsomolsk-on-Amur). E-mail: ktm@knastu.ru.

Виноградов Сергей Владимирович - кандидат технических наук, доцент кафедры «Технология машиностроения» Комсомольского-на-Амуре государственного технического университета (Россия, Комсомольскна-Амуре). E-mail: sergwin72@rambler.ru.

Mr. Sergey V. Vinogradov - PhD in Engineering, Associate Professor, Mechanical Engineering Department, Komsomolsk-on-Amur State Technical University (Russia, Komsomolsk-on-Amur). E-mail: sergwin72@rambler.ru.

Щелкунова Марина Евгеньевна - кандидат технических наук, доцент кафедры «Математическое обеспечение и применение ЭВМ» Комсомольского-на-Амуре государственного технического университета (Россия, Комсомольск-на-Амуре). E-mail: kmopevm@knastu.ru.

Ms. Marina Ye. Shchelkunova - PhD in Engineering, Associate Professor, Software and computer application Department, Komsomolsk-on-Amur State Technical University (Russia, Komsomolsk-on-Amur). E-mail: kmopevm@knastu.ru.

Пронин Александр Иннокентьевич - кандидат технических наук, доцент кафедры «Технология машиностроения» Комсомольского-на-Амуре государственного технического университета (Россия, Комсомольскна-Амуре). E-mail: mdsov@knastu.ru.

Mr. Alexander I. Pronin - PhD in Engineering, Associate Professor, Mechanical Engineering Department, Komsomolsk-on-Amur State Technical University (Russia, Komsomolsk-on-Amur). E-mail: mdsov@knastu.ru.

Самар Елизавета Владимировна - аспирант кафедры «Материаловедение и технология новых материалов» Комсомольского-на-Амуре государственного технического университета (Россия, Комсомольск-наАмуре). E-mail: esamar@inbox.ru.

Ms. Elizaveta V. Samar - a post-graduate student, Material Engineering and Advanced Material Technology Department, Komsomolsk-on-Amur State Technical University (Russia, Komsomolsk-on-Amur). E-mail: esamar@inbox.ru.

Рябов Сергей Александрович - кандидат технических наук, доцент кафедры «Металлорежущие станки и инструменты» Кузбасского государственного технического университета имени Т. Ф. Горбачева» (Россия, Кемерово). E-mail: rsa.msi@mail.ru.

Mr. Sergey A. Ryabov - PhD in Engineering, associate professor, Metal cutters and tool Department, Kuzbass state technical university named after T. F. Gorbachyov (Russia, Kemerovo). E-mail: rsa.msi@mail.ru.

Аннотация. В статье представлена оригинальная систематизация теоретически возможных реализаций компоновочных схем механизмов параллельной структуры, служащая основой для реализации алгоритма расчета геометрических параметров механизма, заложенного в шаблоне, соответствующем данной компоновочной схеме и заданным исходным данным. Представленная систематизация позволяет значительно сократить временные затраты на начальном этапе проектирования механизмов параллельной структуры.

Summary. The article presents an original classification and typing of theoretically possible realizations of layout diagrams containing parallel structure mechanisms that provide the basis for the implementation of the algorithm for calculating the mechanism geometric parameters. The mechanism is embedded in a pattern corresponding to this layout diagram and assigned initial data. The given classification can significantly reduce the time spent on the initial stage of designing mechanisms of parallel structure. 
Ключевые слова: механизм параллельной структуры, приводная штанга, шарнир, металлообрабатывающий станок, компоновка.

Key words: parallel structure mechanism, actuating rod, hinge, metal working machine, the layout.

\section{УДК 621.01}

Одним из новых видов технологического оборудования являются металлообрабатывающие станки с параллельной кинематикой, в которых все рабочие движения подачи сообщаются одному рабочему органу (шпиндельной головке или столу). Основным элементом таких станков является механизм параллельной структуры (МПС) [1].

На сегодняшний день МПС, применяемые в металлообрабатывающих станках, представлены широким разнообразием исполнения (компоновок). Их классифицируют по следующим конструктивным признакам: по виду (постоянной или переменной длины) и количеству приводных штанг; по характеру расположения на платформе и основании шарниров приводных штанг и др. [2].

Многообразие компоновок МПС является следствием разнообразия технологических задач, для решения которых предназначены станки.

Проектирование станка с параллельной кинематикой является трудоемкой конструкторской задачей, сопровождаемой массой промежуточных расчетов, связанных с определением углов размещения шарниров на платформе и основании, увязкой размеров элементов механизма и др.

Автоматизация, позволяющая сократить временные затраты на проектирование, подразумевает формализацию расчетов, т.е. применение в расчетах некоторого шаблона или алгоритма, согласно которому вычислительная машина будет осуществлять вычисления параметров проектируемого механизма, сравнивать рассчитанные варианты между собой.

Авторами предлагается оригинальная систематизация и типизация теоретически возможных реализаций компоновочных схем МПС, позволяющая реализовать конкретный алгоритм задания исходных данных и расчета геометрических параметров механизма, заложенный в шаблоне, соответствующем данной компоновочной схеме.

Для формализации расчетов все теоретически возможные компоновки МПС авторы предлагают разделить на типы, объединяющие в себе компоновки с наибольшим числом общих признаков.

Предлагаемая систематизация теоретически возможных реализаций компоновочных схем МПС позволяет реализовать алгоритм расчета геометрических параметров механизма, заложенный в шаблоне, соответствующем данной компоновочной схеме и заданным исходным данным $[3 ; 4 ; 5]$.

a)

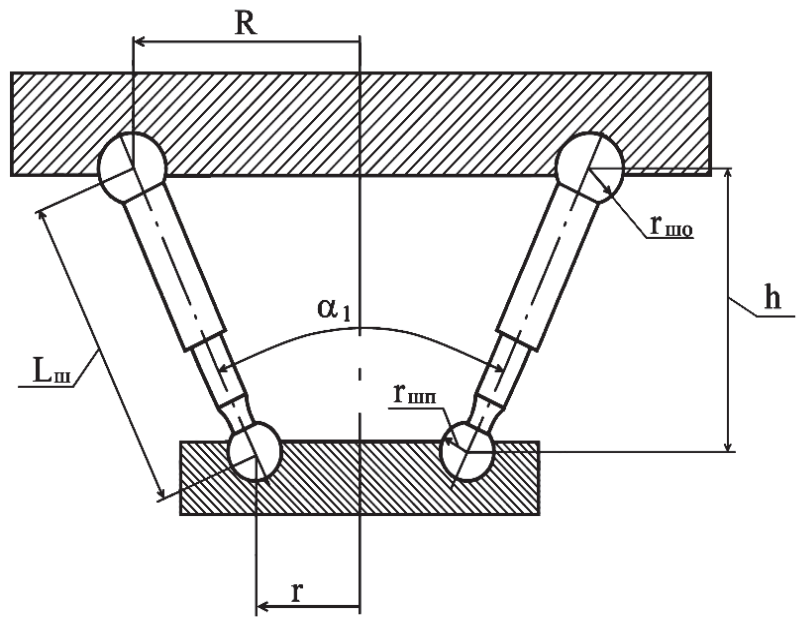

б)

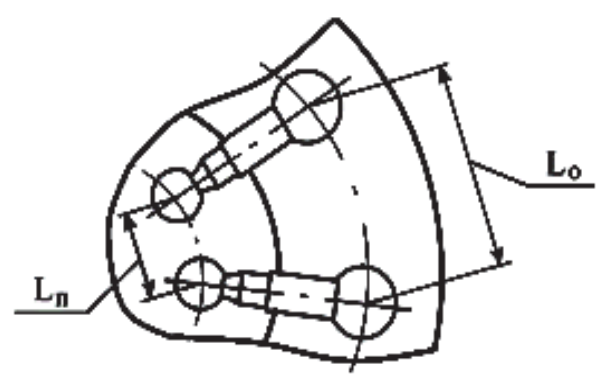

Рис. 1. Конструктивные элементы МПС со штангами переменной длины: a - вид сбоку (сечение); б - расположение штанг в плане 
На рис. 1 условно показаны основные конструктивные элементы МПС, определяющие его компоновку. На рис. 1 использованы следующие обозначения: радиус основания R; радиус подвижной платформы $\mathrm{r}$; расстояние между основанием и платформой $\mathrm{h}$; начальный угол расхождения штанг $\alpha_{1}$; радиусы шарниров на основании $\mathrm{r}_{\text {шо }}$ и подвижной платформе $\mathrm{r}_{\text {шп; }}$; расстояния между шарнирами на основании $\mathrm{L}_{0}$ и платформе $\mathrm{L}_{\text {п }}$; длина штанги $\mathrm{L}_{\text {ш}}$.

Так как большинство известных программных продуктов для расчета параметров МПС ориентированы на проектирование механизмов типа «гексапод» [6; 7], то предлагаемая в работе систематизация представлена на примере МПС с шестью приводными штангами.

Все множество компоновочных схем авторы разделили на две условные группы:

1) симметричные, где все шарниры основания и платформы размещены так, чтобы выполнялось условие симметрии вращения как для подвижной платформы и основания в отдельности, так и для всей схемы в целом. При вращении компоновочной схемы вокруг оси симметрии (прямой, проходящей через центры основания и подвижной платформы) на угол, кратный $120^{\circ}$, она проецируется сама на себя;

2) асимметричные, где размещение шарниров не подчиняется какому-либо порядку.

Среди многообразия типов симметричных компоновок МПС были выделены три частных случая с присвоением им собственных названий:

1) «Равномерная» компоновка (см. рис. 2). Шарниры приводных штанг на основании и платформе размещены равномерно с шагом $60^{\circ}$. Начала отсчета углов на подвижной платформе и основании совпадают. При вращении компоновки вокруг оси симметрии на угол, кратный $60^{\circ}$, она проецируется сама на себя. Такая компоновка чаще применяется при расчетах в теоретических исследованиях.

2) «Попарно параллельная» компоновка (см. рис. 3). Шарниры на основании и подвижной платформе размещены попарно. Пары шарниров расположены через каждые $120^{\circ}$. Хорды (расстояние между осями шарниров) между ближайшими парами шарниров на платформе и основании равны. Хорда между ближайшими шарнирами в паре всегда меньше хорды между ближайшими шарнирами из разных пар. Штанги в каждой паре параллельны друг другу.

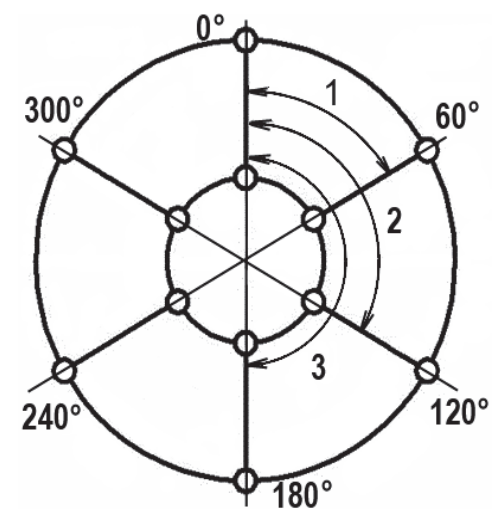

Рис. 2. Конструктивные параметры «равномерной» компоновки МПС: 1, 2, 3 - углы размещения шарниров приводных штанг относительно начала отсчета

3) «Ферменая» компоновка (см. рис. 4). Компоновка так названа за ее сходство с одноименной строительной конструкцией. Шарниры на основании и подвижной платформе расположены попарно. В отличие от «попарно параллельной» компоновки ближайшая пара шарниров на платформе смещена относительно ближайшей пары шарниров на основании на $60^{0}$. При этом хорда в паре всегда меньше, чем хорда между ближайшими шарнирами из разных пар.

Помимо выделенных выше частных случаев, симметричная схема размещения штанг в механизме может быть реализована во множестве вариантов. В предлагаемой типизации компоновок эти схемы обозначены как «другие» симметричные. 


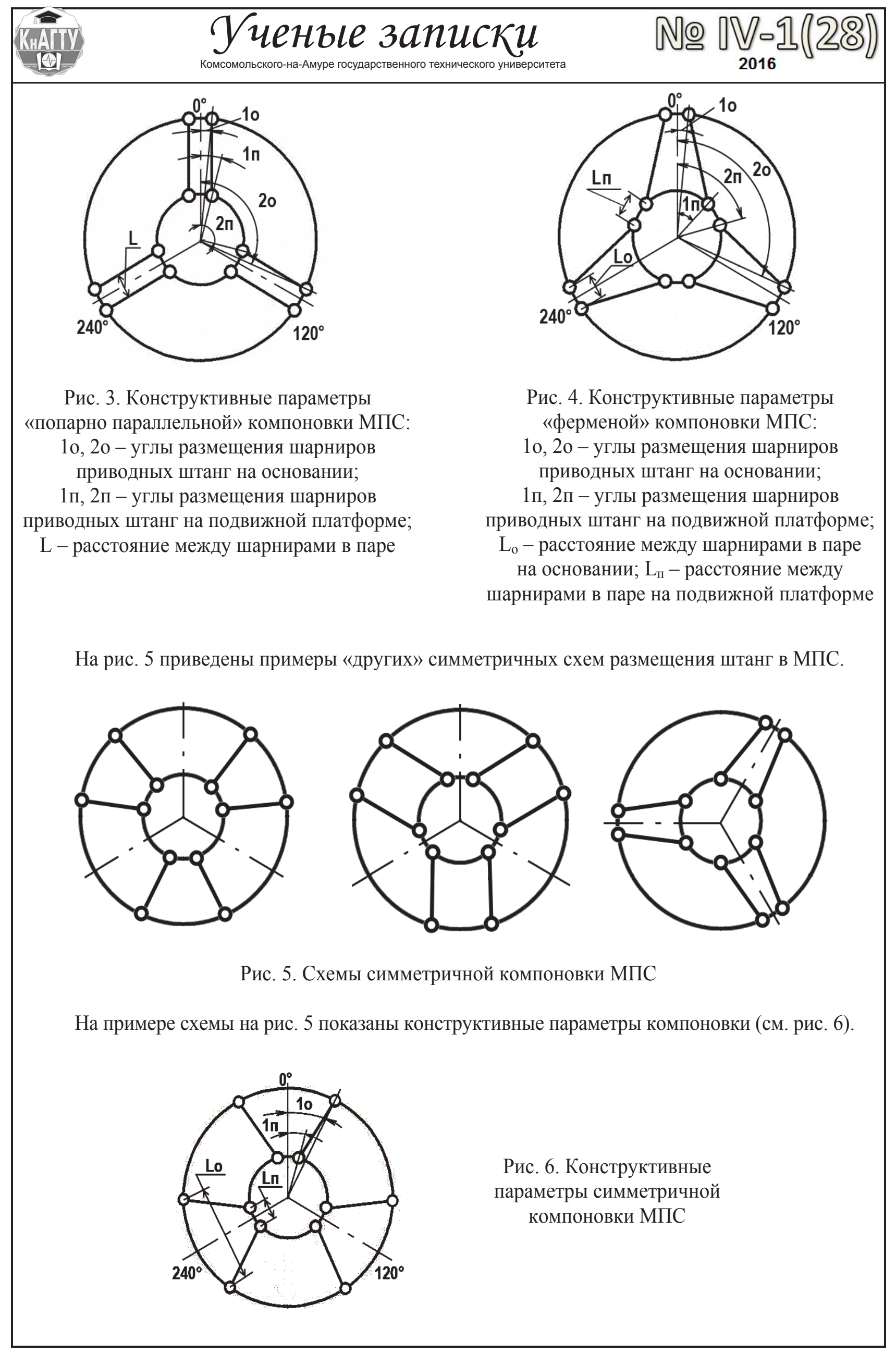


Щелкунов Е. Б., Виноградов С. В., Щелкунова М. Е., Пронин А. И., Самар Е. В., Рябов С. А.

СИСТЕМАТИЗАЦИЯ МЕХАНИЗМОВ ПАРАЛЛЕЛЬНОЙ СТРУКТУРЫ

На рис. 7 показаны примеры асимметричной схемы размещения штанг в механизме, которую можно реализовать в бесконечном множестве вариантов.
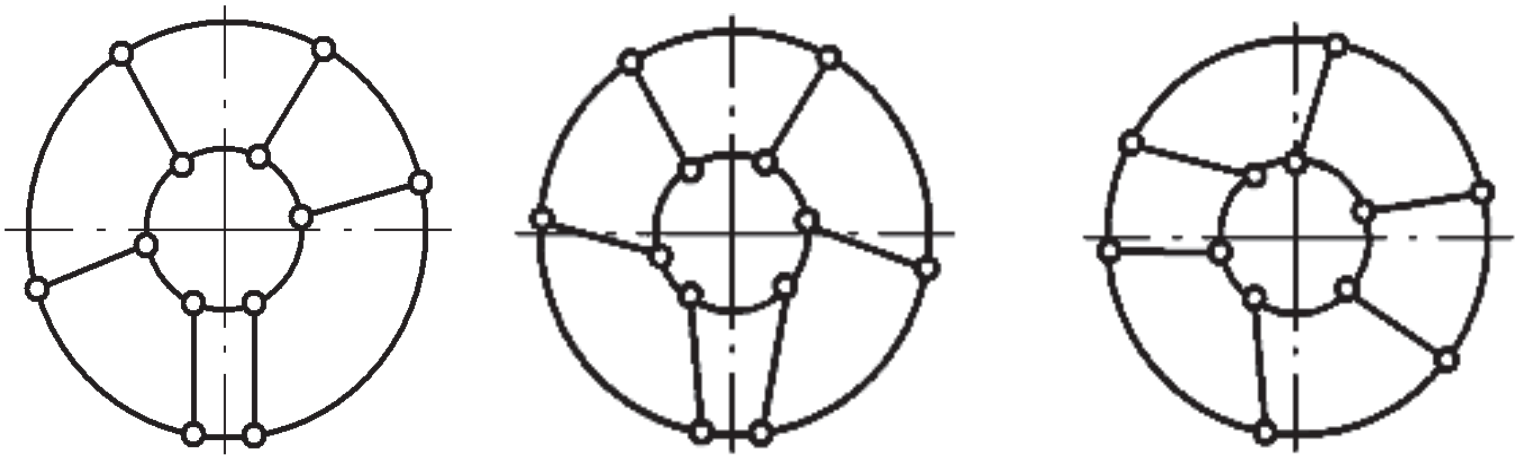

Рис. 7. Схемы асимметричной компоновки МПС

На примере схемы на рис. 7 показаны конструктивные параметры асимметричной компоновки (см. рис. 8). Для асимметричной компоновки углы размещения шарниров приводных штанг на основании и подвижной платформе задаются индивидуально для каждого шарнира.

Предлагаемая систематизация, представленная в работе на примере гексапода, применима и для других типов МПС. В табл. 1 приведена возможная реализация компоновок для МПС с различным количеством приводных штанг. Например, попарно параллельная компоновка может быть реализована в механизмах с четырьмя и с шестью штангами.

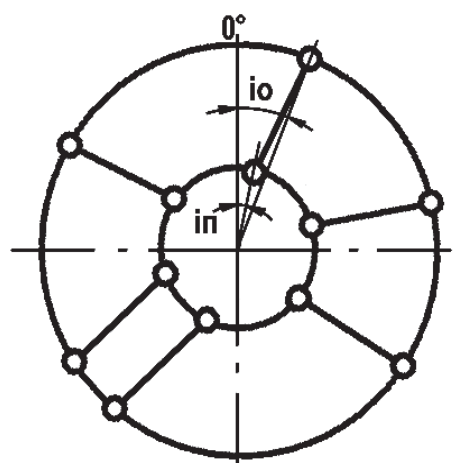

Рис. 8. Конструктивные параметры асимметричной компоновки МПС: iо, іп - углы размещения шарниров на основании и подвижной платформе

Таблица 1

Реализация компоновок для МПС

\begin{tabular}{|c|c|c|c|c|c|c|}
\hline \multirow{2}{*}{\multicolumn{2}{|c|}{ Вид компоновки }} & \multicolumn{5}{|c|}{ Количество приводных штанг } \\
\hline & & 2 & 3 & 4 & 5 & 6 \\
\hline \multirow[t]{4}{*}{ Симметричная } & равномерная & + & + & + & + & + \\
\hline & ферменая & & & + & & + \\
\hline & попарно параллельная & & & + & & + \\
\hline & другая & & & + & & + \\
\hline \multicolumn{2}{|c|}{ Асимметричная } & & + & + & + & + \\
\hline
\end{tabular}

В работе проведена систематизация компоновочных решений для механизмов параллельной структуры. Представленная систематизация позволяет значительно сократить временные затраты на начальном этапе проектирования механизмов параллельной структуры за счет оригинальной формализации всех процессов расчетов и использования готовых шаблонов. 


\section{ЛИТЕРАТУРА}

1. Щелкунов, Е. Б. Металлообработка 2011 / Е. Б. Щелкунов, А. С. Хвостиков // Ученые записки Комсомольского-на-Амуре государственного технического университета. Науки о природе и технике. 2011. - № IV-1(8). - C. 21-30.

2. Щелкунов, Е. Б. Механизмы параллельной структуры в металлорежущих станках / Е. Б.Щелкунов,

С. В. Виноградов, М. Е. Щелкунова, Е. В. Самар // Ученые записки Комсомольского-на-Амуре государственного технического университета. Науки о природе и технике. - 2012. - № IV-1(12). - С. 52-61.

3. Щелкунов, Е. Б. Программа для проектирования механизмов параллельной структуры / Е. Б. Щелкунов, С. В. Виноградов, М. Е. Щелкунова, А. И. Пронин // Ученые записки Комсомольского-на-Амуре государственного технического университета. Науки о природе и технике. - 2015. - № IV-1(24). - C. 46-49.

4. Щелкунов, Е. Б. Автоматизация проектирования механизмов параллельной структуры со штангами переменной длины / Е. Б. Щелкунов, С. В. Виноградов, М. Е. Щелкунова, Д. Г. Посаженников // Технология машиностроения. - 2015. - № 11. - С. 51-55.

5. Щелкунов, Е. Б. Автоматизация проектирования механизмов параллельной структуры / Е. Б. Щелкунов, С. В. Виноградов, М. Е. Щелкунова, М. Ю. Сарилов // Фундаментальные исследования. - 2015. - № 2-17. C. $3748-3752$.

6. Подленко, О. Н. Параметрический синтез формообразующих систем станков на базе механизмов с параллельной кинематикой : дис. ... канд. техн. наук : 05.03.01 / Подленко Олег Николаевич. Хабаровск, 2005. - 145 с.

7. Хольшев, И. Г. Проектирование структуры станков типа тексапод : дис. ... канд. техн. наук : $05.03 .01 /$ Хольшев Игорь Геннадьевич. - М., 2001. - 240 с. 